\title{
Impact of The Pandemic COVID-19 on Consumer Shopping Behaviour in Slovakia
}

DOI 10.18267/pr.2021.krn.4816.21

\author{
Dominika Vernerová \\ ORCID iD: 0000-0002-3636-6659 \\ dominika.vernerova@euba.sk \\ University of Economics in Bratislava, Faculty of Commerce, Department of \\ Marketing, \\ Bratislava, Slovakia
}

\begin{abstract}
At a time of turbulent economic change, e-commerce gives consumers the opportunity to shop without endangering the health of themselves and their relatives, and gives businesses the opportunity to save at least some of their sales and thus protect themselves from a complete drop in sales. The main goal of the paper was to identify the impact of the COVID-19 pandemic on the purchasing decisions of a selected consumer segment and to analyze the factors that most influence them when buying food and emergency goods. By processing the primary data using a chi-square test and histograms, we have came to the conclusion, that the factors that influence consumers when buying vary depending on the range purchased. It can be expected that certain changes in consumer behavior and increased demand for online purchase of certain assortments will persist even after the end of the pandemic.
\end{abstract}

Keywords: consumer behaviour, COVID-19, e-commerce

JEL Classification codes: D10, M10

\section{INTRODUCTION}

Every successful company should carry out thorough analysis of its environment, characterize the key factors that affect the strategic position of the company, and be able to determine what opportunities market development can help them or, conversely, what threats must be prepared in advance (Lesáková, 2014). However, the market economy of each country is currently facing strong downturns, the prediction of which was almost impossible. The onset of the COVID-19 pandemic has often been rapid and influenced by the shopping behavior of consumers who are forced to spend more time at home, making them even more active users in the digital world than before. Changes can be observed not only in the time spent on the Internet, but also in the factors that influenced their purchasing decisions, or in the assortment they bought. Therefore, we consider it important to approach the theoretical basis of the researched issue, which focuses on a new model of consumer behavior - pandemic consumer behavior. Following the theoretical knowledge, a primary survey was conducted, in which we focused mainly on digital consumer activity and its transformation into online shopping. We have also identified differences in factors that affect consumers when buying selected assortment categories. 


\section{LITERATURE REVIEW}

The global pandemic brings enormous economic uncertainty, which on the one hand affects consumers' shopping behavior, but on the other hand also affects the choice of communication by companies. Consumers are postponing their decisions indefinitely, and companies are trying to draw on experience from similar situations in the past, which suggests that their marketing costs will fall sharply. Media consumption is increasing at a tremendous rate, with online media consumption increasing by up to $30 \%$ since the first case of infection in the Slovak Republic (Salner, 2020). People are online more than ever before, which is why social media marketing is gaining prominence, enabling companies to gain huge organic impacts in such a critical period. Businesses have the space to optimize their content, launch Google advertising campaigns, or thoroughly analyze traffic to their website. Changes can also be observed in customer expectations and needs (Shipley, 2020). While a few months ago they considered the price of products and services a priority, they decided according to which company is more environmentally friendly, which store they have near their home, or which product they had the opportunity to try in retail premises, today everything is different. Today, they need to be first and foremost informed that the company has secured hygiene, that it takes care of the health of its employees, that it has control over the distribution of its products, and therefore that they can always turn to the company. The delivery time of the product also plays an important role today, about which customers must be informed in advance. Every marketing activity in these turbulent times should also include the sincerity with which the company will ensure the long-term loyalty of its customers. If companies want to respond promptly to customer needs, they must have a strong customer service team that regularly provides them with information on current market developments, which is conditioned by turbulent fluctuations in each area of business.

Consumer behavior can be characterized as a process of deciding on the use of available resources, under which we include the energy, time and money needed for consumption itself (Solomon, 2013). It is a process in which subjects purchase and consume products or services through which they satisfy their needs (East, 2017). Factors that influence consumer behavior can include culture, social status, family, friends, consumer interests, motivation, perception and many others (Richterová, 2015). As early as 1990, consumer behavior was defined by the American Marketing Association (AMA) as a dynamic combination of consumer interaction, knowledge, behavior, and life events. The corona crisis has affected all people, regardless of their age, gender or the country in which they are located, which also has a significant impact on the products and services they buy. Characteristic features of consumer behavior during the pandemic are shown in fig. 1.

Fig. 1 Pandemic Consumer Behavior



Source: own processing according to Sheth, 2020 
1. Stockpilling - according to Wang (2020), household food storage created a demand shock, especially in the food market. There is an increase in the volume of purchases of daily consumer goods, which increases stocks in households and causes temporary shortages in retail store. This fact could be observed especially in the beginning of the pandemic, which surprised manufacturers, suppliers, traders and final consumers, and partially disrupted the entire supply chain. Among the scarce goods we could include, for example, toilet paper, bread and durable food. However, the excessive accumulation of food stocks can also have negative aspects in the form of increased food waste (Long, 2020).

2. Change in demand - the impact of a pandemic can also be observed in reduced demand for consumer durables, social events, or demand for services, which is largely influenced by the state of emergency persisting in countries around the world. On the contrary, there is a growing demand for digital products such as online courses, education or membership on digital platforms, on which consumers are more active than ever before. Demand has also increased in the category of alcoholic beverages, pharmaceuticals and household products (McKinsey, 2020). It is also worth mentioning the enormous increase in demand for the so-called emergency goods, which include drapes, gloves, wet wipes, or disinfectant gels (Nielsen, 2020).

3. Improvisation - as a result of government regulations that seek to prevent the spread of a pandemic, consumers are forced to spend more time at home, which affects their daily activities as well as specific life events. Improvisation and the transition to the digital sphere could also be observed in traditions, for example through online services for Easter, Christmas, or online weddings through various digital platforms. It is also necessary to mention that companies must also improvise, as they are forced to look for online solutions even for off-line problems that come from customers every day. If companies manage to provide their customers with alternative solutions to their problems (ideally without physical or personal contact), whether in the form of applications, home production instructions, or in the form of home delivery services, consumers will feel support and affection for brand's products and services, which can have a positive effect on their current as well as future purchasing decisions (Ho, 2020).

4. Digital Literacy - in times of a pandemic, the internet is an integral part of every household. Thanks to the Internet, it is possible to communicate with the outside world, do your work from home or fill your free time, which also has an impact on increasing the digital literacy of Slovak consumers. The impact of social networks on consumer behavior is huge, which is why companies try to use them mainly for modern forms of marketing. An effective tool can be a properly set up influencer marketing, which in the current situation is used by brands up to $33 \%$ more often than it was before the outbreak of the pandemic. Even though the consumer does not have the space to test his product directly in the store, the promotion of a famous person through various social media can encourage him to buy. The most effective platforms for Influencer Marketing are the social networks Instagram and TikTok, where there has been a recent 76 percent increase in impressions (Perelli, 2020).

5. Expanding hobbies and talent - the pandemic boosted consumer creativity and also changed the way they spend their free time. Everyday hectic life has slowed down a bit, so consumers have room to experiment with cooking, expand their talent, renovate homes, or shop online, which is driven by increased demand in certain categories, which we mentioned in the previous part of the article.

6. Delivery services - last but not least, the pandemic also affected the logistics of the last mile, in which we include the services of courier and forwarding companies. 
Consumers are gradually getting used to delivering products directly to their doors, which will save them time and also protect their health in a pandemic situation (Sheth, 2020). The use of delivery services has increased, as restaurant and café services have also operated in a restricted mode, and the home food service, which many consumers have tried for the first time during a pandemic, has also become popular.

\section{METHODOLOGY}

The main goal of the paper was to identify the impact of the COVID-19 pandemic on the purchasing decisions of a selected consumer segment and to analyze the factors that most influence them when buying food and emergency goods. The starting point was the collection of secondary data from domestic and foreign professional sources, from which we created a theoretical basis for the researched issues based on the scientific method of synthesis, deduction and comparison. The next step was the implementation of the primary survey through an anonymous questionnaire in electronic form. We chose Slovak consumers in the age range from 16 to 32 as the target group of the questionnaire, as we consider them to be the segment with the largest consumption of digital media, which is the basis of our assumption that they have experience with online shopping, so they can be considered as a relevant sample. Despite the fact that twelve respondents in the lowest age category (16-18 years) could only have been 15 years old before the pandemic, after a detailed analysis of their answers, they can be classified as active internet users who occasionally shop online. Therefore, we decided to include this consumer segment among the examined sample. The questionnaire contained 28 questions, which were divided into three sections. Two sections contained identical questions, the difference was in before and after the pandemic. Based on these questions, it was possible to compare consumer behavior over two periods and identify the main changes that took place during the pandemic. The questionnaire was filled by 587 respondents from all over Slovakia, but most respondents were from Bratislava Region (17.4\%), Žilina Region (16.5\%) and Prešov Region (13.6\%).

Based on the application part of the paper, we will try to answer the following research questions:

- Research question 1: Which attribute do consumers consider most important when buying food?

- Research question 2: Which attribute do consumers consider most important when buying emergency goods?

The research questions are complemented by the formulation of the following hypothesis:

- H1: There is a dependence between the time spent on the Internet and the rate of online shopping.

We analyzed the collected data in the IBM SPSS statistical program, and also used histograms, contingency tables, and a chi-square test. For a contingency table with frequencies $n_{i j}$ and expected frequencies $e_{i j}$, we define the quantity chi-square by the relation:

$$
\chi^{2}=\sum_{i=1}^{r} \sum_{j=1}^{c} \frac{\left(n_{i j}-e_{i j}\right)^{2}}{e_{i j}}
$$

Where:

$$
\begin{aligned}
& n_{i j}-\text { actual number } \\
& e_{i j} \text { - expected number }
\end{aligned}
$$


The quantity $\mathrm{X} 2$ is the basis for the hypothesis test on the independence of factors $A$ and $B$. Its small values speak in favor of the hypothesis, large values not in favor of the hypothesis.

If the $\chi^{2}>\chi_{(r-1)(c-1)}^{2}(\alpha)$ hypothesis about the independence of factors $A, B$ is rejected on the level $\alpha$.

\section{RESULTS AND DISCUSSION}

The structure of the questionnaire survey was compiled in such a way that it was possible to compare the behavior of consumers on individual issues in two periods:

1. before the pandemic - the period before March 2020,

2. after the outbreak of the COVID-19 pandemic - the period from March 2020 to the present.

Calculation of the sample size:

$n=\frac{z^{2} * p *(1-p)}{c^{2}}=\frac{1,96^{2} * 0,5 *(1-0,5)}{0,05^{2}}=384,16$

For the $95 \%$ confidence level, the allowable error margin of $5 \%$ and the character ratio of 0.5 is the minimum sample size of 384 respondents. The structured questionnaire was filled by 587 respondents aged between 16 and 32 years. The survey was carried out through an anonymous questionnaire, which was shared on social networks in the period from 7 January 2021 to 21 January 2021. As the sample consisted mainly of young people, $83.5 \%$ were students, $10.2 \%$ were employed, $1.9 \%$ respondents were unemployed, $1.9 \%$ of respondents stated that they were on maternity leave and $0.9 \%$ indicated that they were self-employed. $56 \%$ of respondents come from the city and $44 \%$ of respondents live in the village.

\subsection{Internet shopping via e-shops}

Fig. 1 Comparison of digital media consumption in Slovakia

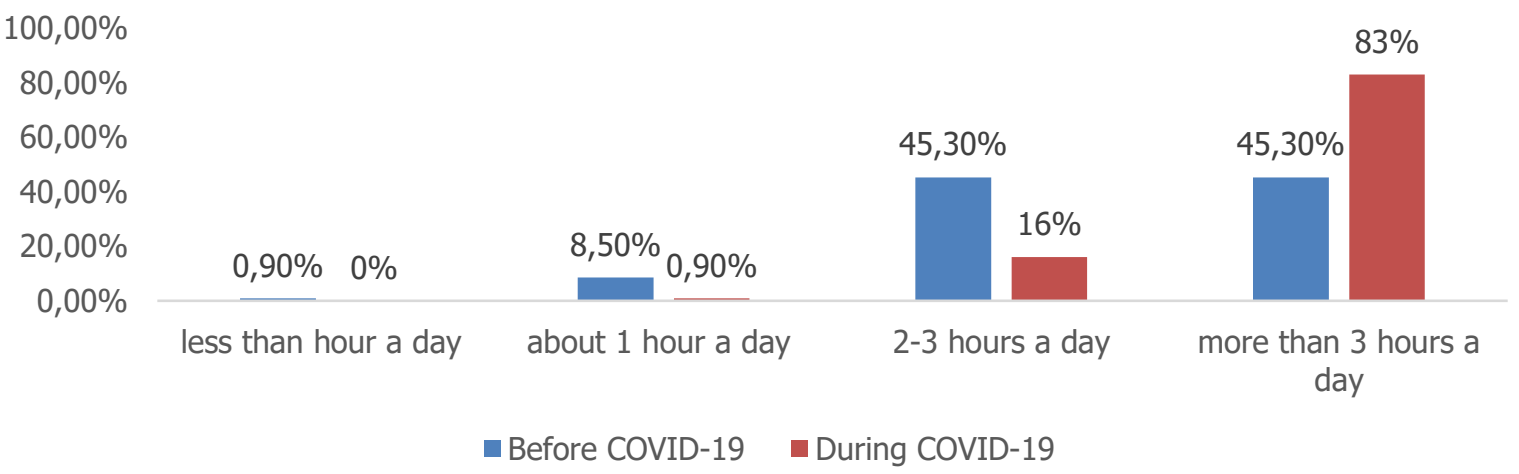

Source: survey results

According to the answers of the respondents, it can be stated that the activity of Slovak consumers in the digital space was already at a very high level before the outbreak of the pandemic. Less than $1 \%$ of respondents said they spent an average of less than 1 hour a day 
on the Internet before a pandemic. $45 \%$ of respondents stated that they spent about 2 to 3 hours a day on the Internet, and the same proportion of responses could be observed for more than 3 hours a day. With an identical question concerning the digital activity of Slovaks during the pandemic, it was possible to observe a significant increase in media consumption, as the option of more than 3 hours a day was chosen by up to $83 \%$ of respondents. We also used questions in the survey to find out the preferences of Slovaks when shopping online. $25.2 \%$ of respondents shopped online often before a pandemic, 71.2\% used e-shops rarely, and 3.6\% said they never bought online. These percentages changed significantly with the same question during the corona crisis, as as many as $47.2 \%$ of respondents said they shop online often during a pandemic, and only $0.9 \%$ said they did not shop online during a pandemic.

\section{Fig 2 Frequency of online shopping before the COVID-19}

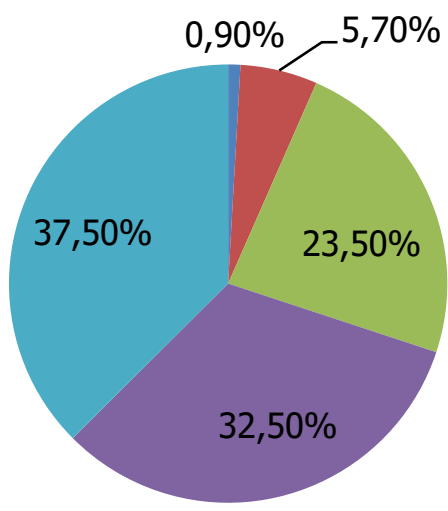

n several times a week

nonce a week

2-3 times a month

monce a month

less than once a month

Source: survey results

Fig. 3 Frequency of online shopping during the COVID-19



n several times a week

once a week

2-3 times a month

monce a month

less than once a month

Source: survey results

In the period before the pandemic, $37.5 \%$ shopped online less than once a month, from which we judge that these are respondents who preferred to buy in brick-and-mortar stores or did not shop at all. On average, $32.5 \%$ of respondents used e-shop shopping once a month, and only $0.9 \%$ of respondents shopped on the Internet regularly. During the pandemic, these conditions changed. The number of regular online purchases increased (4.8\%), $13.9 \%$ of respondents shopped once a week, and a significant proportion of respondents used online shopping 2 to 3 times a month. Only $16 \%$ of respondents bought less than once a month, which represents a $56 \%$ decrease compared to the period before the pandemic. $58.6 \%$ of respondents during the pandemic preferred online shopping from domestic e-shops, while the main categories of assortment, according to the survey, can be considered clothing and 
footwear, electronics, drugstore goods and books. An increase was also observed in the range of pharmaceutical products, where before the pandemic only $6.7 \%$ of respondents bought these products over the Internet, while during the pandemic the rate of online purchase of this range increased to $14.6 \%$. Before the pandemic period only $2.8 \%$ of respondents bought food online, during the pandemic this percentage increased to $13.1 \%$. When asked if they used the "Food Home" service before the pandemic, 94.5\% of respondents answered no, 1.9\% said that they tried this service once, and only $3.5 \%$ of respondents used this service regularly. $86.1 \%$ answered no to an identical period-oriented question during a pandemic, $5.5 \%$ used it once and $8.4 \%$ used it regularly. According to a PwC survey, there was an increase in online shopping during the pandemic, especially in the categories of frozen foods (27\%), fast food spoilage (26\%) and household cleaning supplies (21\%) (PwC, 2021). Kohli et. al. (2020) in their study point out that the pandemic also significantly affected the size of shopping baskets, reduced the frequency of purchases in stores and increased the demand for electronic purchasing of food and pharmaceutical products. Puttaiah (2020) points out that changes such as digital adoption or health awareness will persist in society even after the pandemic has been over, and that it is therefore important to adapt business activities accordingly. Zwanka and Buff (2020) confirm this fact and point to the trend of increasing the frequency of food purchases through online stores, which is likely to last longer than the fight against the COVID19 pandemic itself. According to KMPG's online surveys (2020), it was possible to observe an increase in e-shopping in 2020 in all segments, while sales volumes in stores decreased. (39\% decrease in the food segment). This is also confirmed by the results of our survey, in which it was possible to observe a $22 \%$ increase in the frequency of online purchases compared to the period before the pandemic. Troy (2020) states that in the category of online shopping it was possible to observe an increase of up to $33 \%$ compared to 2019 , specifically in the preChristmas period. As our primary data collection was carried out at the beginning of 2021, we also dealt marginally with the issue of pre-Christmas shopping behavior. For example, we were interested in the extent to which the pandemic affected the proportion of Christmas gifts purchased in stores and e-shops. In previous years, up to $43 \%$ of respondents shopped more in malls, and only $1,5 \%$ said they preferred buying Christmas presents through e-shops. There were significant changes in the purchase of Christmas gifts in 2020 , as up to $31 \%$ of respondents shopped only through the e-shop, and only $4.6 \%$ of respondents shopped exclusively in shopping males (a decrease of 12\%).

An important part of the survey was also the analysis of factors that affect consumers when shopping. Using a scale question, we found out to what extent the following factors influence the respondents: 1. the price of the product / service, 2. quality, 3. availability in stock, 4. delivery time, 5. delivery price, 6. reviews on the Internet, 7. recommendations, 8. ecological aspects, 9. possibility to pick up the goods in person at the store, 10. possibility to pick up the goods at the box/mailroom. Respondents rated individual factors on a scale from 1 to 4 , where 1-does not affect me at all, 2-less affects me, 3-affects me, 4-affect me a lot. An overview of the results is shown in the figure 4.

According to the survey, we can state that the most important factors in purchasing decisions during a pandemic considered by Slovak consumers are: price of the product, the quality of the product and the price of delivery of goods. Significant influence can also be observed in factors related to the distribution of goods. The availability of goods in stock during a pandemic is important for $72 \%$ of respondents, the price for delivery is greatly affected or influenced by $83 \%$ of respondents, and $64 \%$ of respondents also decide according to the delivery time. There was also a decrease in the "recommendations"factor, where before the pandemic, up to $56 \%$ of respondents considered this factor important, during the pandemic only $23 \%$ of respondents stated this. In both monitored periods, a low involvement of Slovak consumers in improving the quality of the environment can also be observed. Environmental aspects such as the delivery of a product by electric car or eco-packaging affect consumers to a very low 
extent compared to other factors, as up to $61 \%$ of respondents stated that this factor affects them less or not at all.

\section{Fig. 4 Influence of factors on online shopping during the COVID-19}

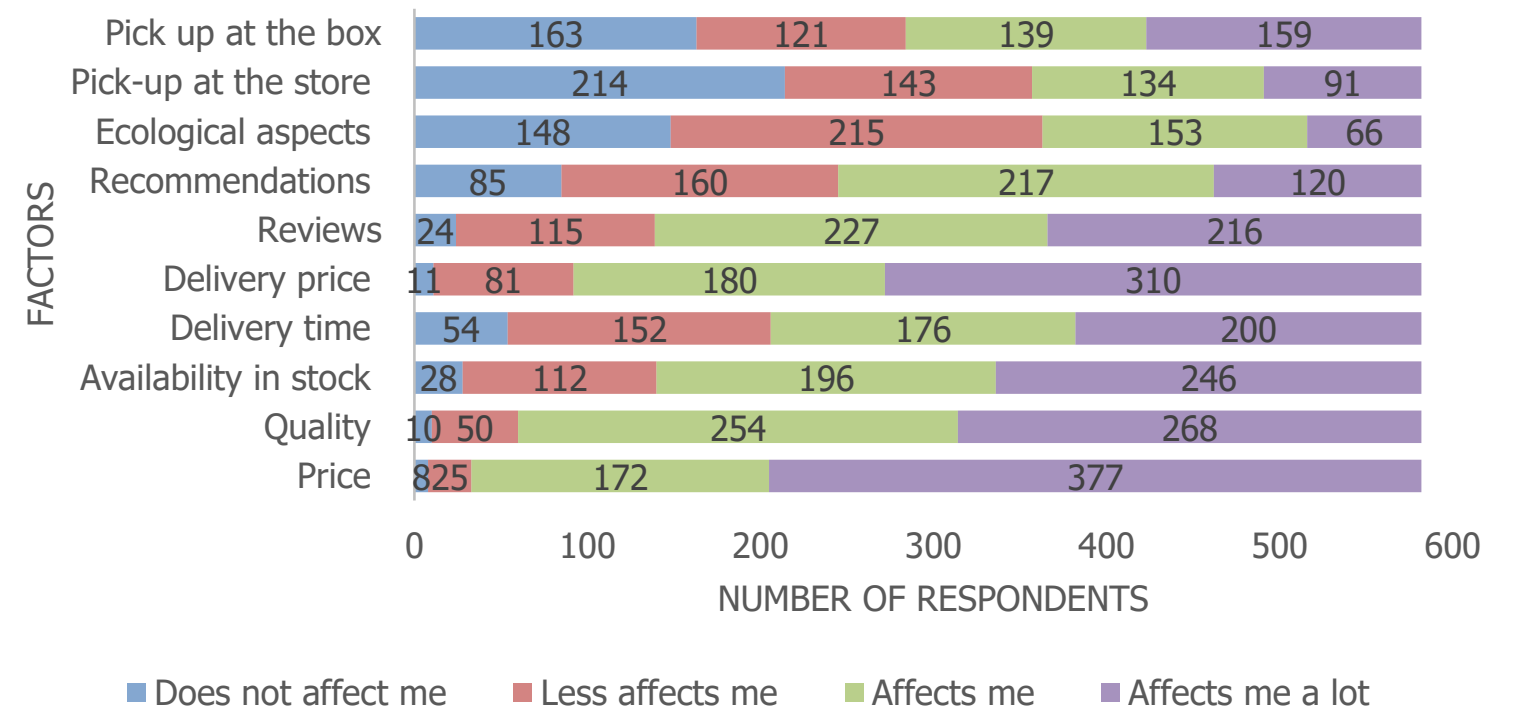

Source: survey results

As we focused on the digital activity of Slovak consumers focused on shopping through eshops, our first test assumption is that there is a direct relationship between time spent on the Internet and the rate of online shopping.

HO: There is no dependence between the variables time spent online and the rate of online shopping.

H1: There is a dependence between the time spent on the Internet and the rate of online shopping.

\section{Tab.1 Interdependence verification}

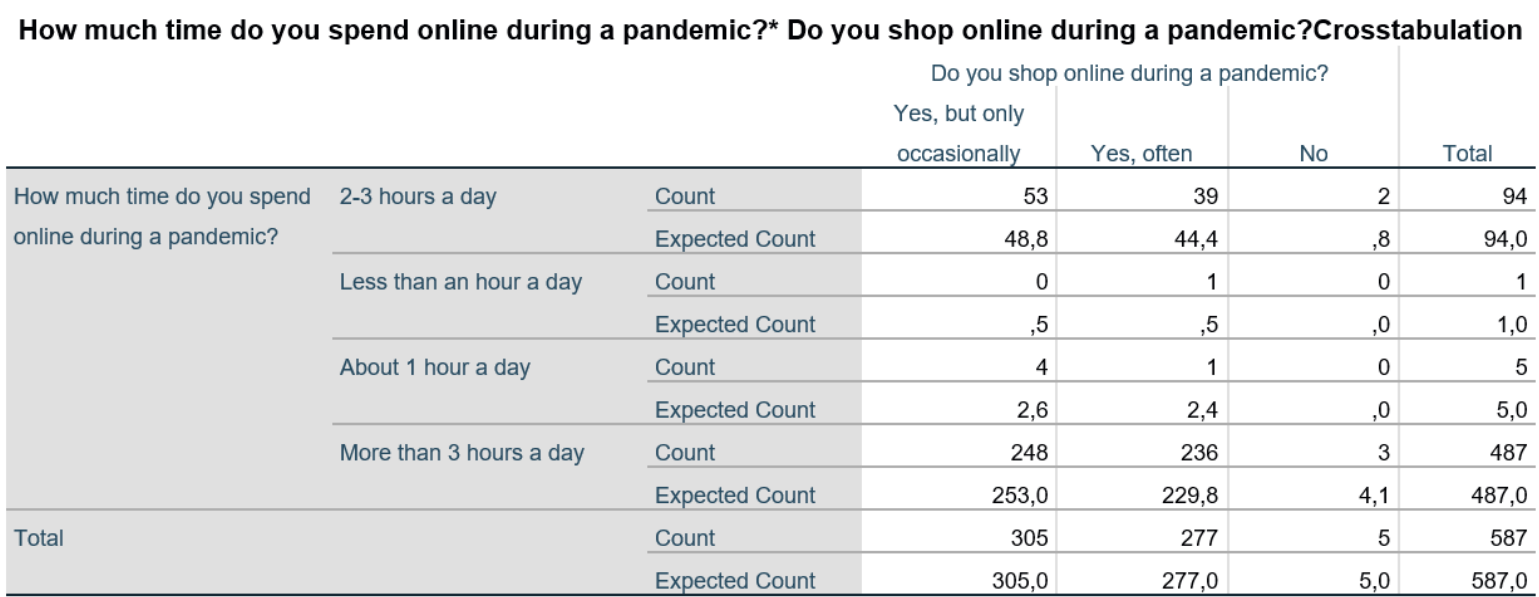

Source: author's own processing 
Tab. 2 Independence tests

\begin{tabular}{|l|c|c|l|}
\hline \multicolumn{5}{|c|}{ Chi-Square Tests } \\
\hline & Value & df & Exact Sig. (2-sided) \\
\hline Pearson Chi-Square & $6,084 a$ & 6 &, 204 \\
\hline Likelihood Ratio & 6,138 & 6 &, 252 \\
\hline Fisher's Exact Test & 10,357 & &, 192 \\
\hline N of Valid Cases & 587 & & \\
\hline a. 8 cells $(66,7 \%)$ have expected count less than 5. The minimum expected count is, 01. \\
\hline
\end{tabular}

Source: author's own processing

The dependence between time spent online and online shopping rates has not been confirmed. Because 8 cells have a lower expected value than 5, we cannot use the classical Pearson Chi square test, so we use Fisher's exact test. At the level $=0.05$, we accept the null hypothesis of independence between variables. This was also confirmed in another question of the survey, in which we asked respondents how they spend time on the Internet. As many as $96 \%$ of respondents spend their free time during a pandemic very often or often on social networks. $79 \%$ of respondents stated that they spend their time online watching series, and only $55 \%$ of respondents indicated the possibility of shopping online. There is no direct dependence between the selected variables and therefore it cannot be assumed that with the increased online activity of Slovaks, the volume of purchases via the Internet will also increase.

\subsection{Shopping behavior of food and emergency goods}

Another part of the survey was to examine the differences in the purchase of food and emergency goods. We assumed the difference in the importance of individual factors in the purchase of everyday consumer goods (mostly food) and in the purchase of emergency goods, which we can consider during the pandemic drapes, gloves, disinfectant gels. The emergency goods category uses an intensive distribution strategy that ensures a prompt response to the daily demand for the goods and ensures its availability in retail units where it is available to final consumers. Shortcomings in the supply of emergency goods arose, especially in the first months of the pandemic, which also had an impact on the significant increase in the price level of individual products, as market demand sharply exceeded supply.

The aim of the analysis of the survey results was to answer the following research questions:

Research question 1: Which attribute do consumers consider most important when buying food?

Research question 2: Which attribute do consumers consider most important when buying emergency goods?

Comparisons of consumer preferences in selected two categories are shown in the form of histograms in the following figures. 
Fig. 5 Food purchase priorities

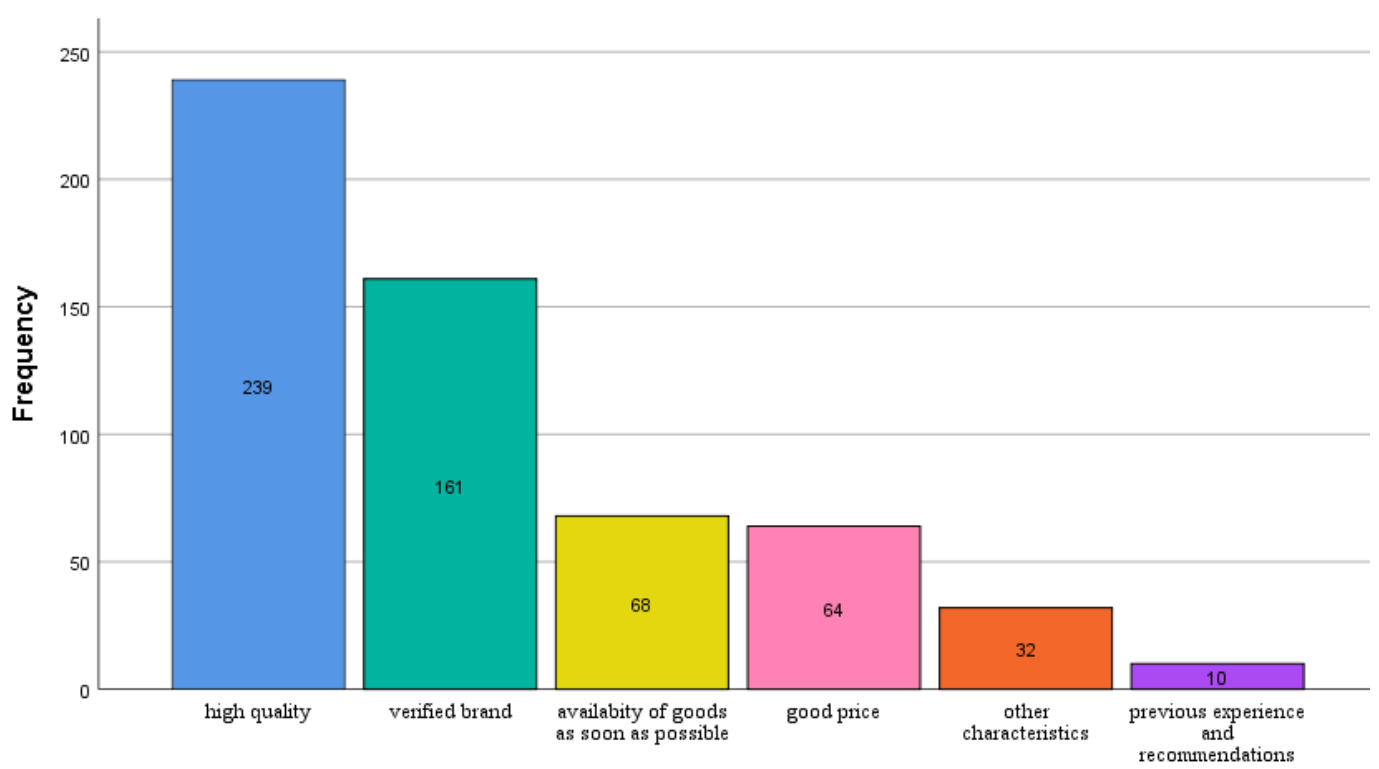

Source: author's own processing

Fig. 6 Emergency goods purchase priorities



Source: author's own processing

Based on the results of the numbers from the implemented survey, which we present in the form of a histogram, it can be stated that the most important factor considered by Slovak consumers is the high quality of the product, regardless of whether it is buying food or emergency goods. Specifically, 41.6\% (239) of respondents chose quality as a priority factor when buying food, $39.9 \%$ (231) of respondents chose this option in a question focused on the purchase of emergency goods such as drapes, gloves, disinfectant gels. The differences can be seen in the second most numerous answer. In the food segment, $28 \%$ (161) of respondents say that the verified brand is important for them. When buying emergency goods, it is 
important for $39.9 \%$ (138) of consumers to have the goods available as soon as possible. Here we can observe a significant difference, which results mainly from the fact that the availability of emergency goods in retail operations was very low, especially in the early months of the pandemic. Operations were not prepared for an enormous increase in demand for this segment, which was also reflected in the increase in the price level, when the consumer paid three times the standard price for selected goods such as disinfectant gel. This is the basis for the third most numerous answer, in which $15.2 \%$ (88) of respondents state that it is important for them that emergency goods have a favorable / good price. The quality, availability and price of emergency goods can therefore be considered the most important factors that affect the shopping behavior of Slovak consumers during the COVID-19 pandemic, and the brand $(5.9 \%)$, previous experience and recommendations (2.9\%) affect shopping decision making at least. $12.3 \%$ of respondents also state that the highest priority for them when buying emergency goods is other characteristics, such as the unique appearance of the drape or the skin-friendly disinfectant gel. When buying food, we consider the quality, brand and availability of the product to be the most important decision factors. Only $11.1 \%$ of respondents chose the price of the product, from which we conclude that Slovak consumers prefer quality food and mostly brands that they know well and that they buy at regular intervals.

\section{CONCLUSION}

The main goal of the paper was to identify the impact of the COVID-19 pandemic on the purchasing decisions of a selected consumer segment and to analyze the factors that most influence them when buying food and emergency goods. The pandemic consumer behavior speaks of the major changes taking place in 2020. It is mainly an increase in the volume of stocks in households in which the demand for durable foodstuffs, alcoholic beverages, pharmaceutical products or assortment intended for domestic work has increased. The decline was recorded in the demand for social events, services or durable goods. Another characteristic of pandemic consumer behavior is the increased consumption of online media, the use of courier and forwarding companies, or differences in leisure time. The results of the survey confirm the increase in digital activity of Slovaks, as well as their rates of online shopping. During a pandemic, consumers buy more from domestic than foreign e-shops and most often buy clothes, shoes, electronics and books online. Before the pandemic, consumers shopped through e-shops on average once a month, during the pandemic this frequency increased to 2-3 times a month. Changes could also be observed in the purchase of Christmas gifts, where there was a $29 \%$ increase in preference for online shopping. The most important factors that influence consumers when shopping online during a pandemic can be considered the price of the product, the quality of the product and the price of delivery of the product. Factors related to the distribution of goods, such as the time of delivery and the availability of goods in stock, also appear to be important. The increase in importance could also be observed during the pandemic with the factor of the possibility to pick up the goods in the shop, which is derived mainly from the government's ongoing measures, based on which shopping in stone shops is limited. There is no direct relationship between time spent on the Internet and the rate of shopping through e-shops, and therefore it cannot be assumed that increased digital activity of Slovaks will have a positive effect on online shopping through e-shops. Respondents most often spend their time on the Internet on social networks, watching serials, and only then is online shopping mentioned. When verifying the most important attributes of decision-making when purchasing food and emergency goods, the answers were consistent, as the largest number in both categories represented the quality of the product. In the case of food, consumers also consider the product brand and the availability of goods to be important but on the other hand, recommendations and the price of the product are not a priority for them. For emergency goods such as drapes, gloves, disinfectant gels, it is important for consumers to have the goods available as soon as possible and to prioritize a reasonable price. All this 
can be deduced from the insufficient supply of this range, especially in the early days of the pandemic, which caused a rapid increase in the price level.

\section{ACKNOWLEDGEMENT}

This paper is output of the project VEGA $1 / 0046 / 20$ "Consumer attitude towards electromobility in the automotive market in the Slovak Republic. "

\section{REFERENCES}

East, R. (2017). Consumer Behaviour - Applications in Marketing. Singapore: SAGE Publications Ltd.

Ho, C. (2020). Innovating in Challenging Times. Retrieved 1 February 2021, from https://www.ipsos.com/sites/default/files/ct/publication/documents/2020-03/innovating-inchallenging-times-2020-ipsos_3.pdf

KMPG (2020). COVID-19 is changing consumer behavior worldwide; business needs to adapt rapidly. Retrieved 15 March, from https://home.kpmg/ro/en/home/media/pressreleases/2020/12/covid-19-is-changing-consumer-behavior-worldwide---business-need.html

Kohli et. al (2020). How COVID-19 is changing consumer behavior -now and forever. Retrieved 15 March 2021, from https://b2bsolutionsllc.com/wp-content/uploads/2020/12/McKinseyCompany-how-covid-19-is-changing-consumer-behaviornow-and-forever.pdf

Lesáková, D. (2014). Strategický marketing. 1.vyd. Bratislava: Sprint 2 s.r.o.

Long, N.N. \& Khoi, B.H. (2020). An Empirical Study about the Intention to Hoard Food during COVID-19 Pandemic. EURASIA Journal of Mathematics, Science and Technology Education, Vol.16 (7). ISSN:1305-8223.

McKinsey (2020). A global view of how consumer behavior is changing amid COVID-19. Retrieved 13 January 2021, from https://Ink.sk/ezcj

Nielsen (2020). Covid-19 mení nákupné správanie slovenských spotrebitel'ov. Retrieved 20 January 2021, from https://www.nielsen.com/sk/sk/insights/article/2020/covid-19-meninakupne-spravanie-slovenskych-spotrebitelov/

Perelli, A. (2020). How the coronavirus is changing the influencer business, according to marketers and top Instagram and YouTube creators. Retrieved 13 January 2021, from https://lnk.sk/aCJ7

Puttaiah, M. (2020). All change: how COVID-19 is transforming consumer behaviour. Retrieved 15 March 2021, from https://www.swissre.com/institute/research/topics-and-riskdialogues/health-and-longevity/covid-19-and-consumer-behaviour.html

PwC (2020). Evolving priorities: COVID-19 rapidly reshapes consumer behavior. Retrieved 15 March 2021, from https://www.pwc.com/us/en/industries/consumer-markets/library/covid19-consumer-behavior-survey.html

Richterová, K. et.al. (2015). Spotrebitel'ské správanie. Bratislava: Sprint 2 s.r.o.

Salner, A. (2020). Marketing ovplyvnený pandémiou. Retrieved 13 January 2021, from https://Ink.sk/tKL8

Sheth, J. (2020). Impact of Covid-19 on consumer behavior: Will the old habits return or die? Journal of Business Research, Vol. 117, pages 280-283. https://doi.org/10.1016/j.jbusres.2020.05.059 
Shipley, K. (2020). Crisis marketing: How brands are addressing the coronavirus. Retrieved 1 February 2021, from https://www.thinkwithgoogle.com/future-of-marketing/digitaltransformation/coronavirus-crisis-marketing-examples/

Solomon, M. et.al. (2013). Consumer Behaviour - Buying, having, being. $3^{\text {rd }}$ Edition. Malaysia: Pearson Australia Group Pty Ltd.

Troy, M. (2020). The Unexpected Consequences of the COVID-19 Christmas. Retrieved 15 March, from https://progressivegrocer.com/unexpected-consequences-covid-19-christmas

Wang, E., An, N., Gao, Z., Kiprop, E., \& Geng, X. (2020). Consumer food stockpiling behavior and willingness to pay for food reserves in COVID-19. Food Sec. 12, 739-747. https://doi.org/10.1007/s12571-020-01092-1

Zwanka, J.R \& Buff, Ch. (2020). COVID-19 Generation: A Conceptual Framework of the Consumer Behavioral Shifts to Be Caused by the COVID-19 Pandemic. Journal of International Consumer Marketing. ISSN: 0896-1530. https://doi.org/10.1080/08961530.2020.1771646 